\title{
A retrospective study on emergency visits in two hospitals in Sherbrooke, Canada
}

\author{
Lourdes Zubieta' ${ }^{1}$, J osé Ramón Fernández-Peña² \\ 1. Williams School of Business, Bishop's University, Sherbrooke, QC, Canada. 2. Health Education Department, College of
} Health and Social Sciences, San Francisco State University, USA.

Correspondence: Lourdes Zubieta. Address: Williams School of Business, Bishop's University, Sherbrooke, QC J 1M 1Z7 Canada. E-mail: Izubieta@ubishops.ca

Received: December 11, 2013

Accepted: January 22, 2014

Online Published: March 13, 2014

DOI : $10.5430 /$ jha.v3n4p61

URL: http://dx.doi.org/10.5430/jha.v3n4p61

\begin{abstract}
Non-urgent use of Emergency Departments throughout Canada has long presented a conundrum for hospital administrators and health service planners. On the one hand, perceptions persist that those non-urgent users contribute to overcrowding, higher costs of care and longer wait times. On the other hand, non-urgent users do not appear to increase wait times for high-acuity patients; they perceive their condition to be acute, or claim not having convenient access to primary medical services. The objective of this study is to investigate factors associated with emergency demand for minor conditions using administrative data as well as geographical and socioeconomic characteristics as captured by Pampalon's deprivation indexes. We reviewed 42 months of administrative data (2006 - 2009) of minor emergency visits in two hospitals in Sherbrooke, QC, Canada. Data mining algorithms were applied to classify the visits and detect major utilization patterns of Sherbrooke residents. Lower priority visits (CTAS 5) continued to increase in the city hospital following a remodel. Adult residents tend to choose the closest ED, and children mainly go to the regional hospital ED. The use of ED for minor conditions (CTAS level 4 and 5) was higher in the most deprived communities, whether materially or socially. The most common diagnostic codes were injuries and poisoning, ill-defined conditions, respiratory problems, digestive system problems, musculoskeletal, and mental health conditions, with $15 \%$ of the visits not completed because patients left before seeing a doctor. Two Sherbrooke boroughs, with no walk-in clinics, generated the majority (57\%) of all non-urgent visits. We forecast the reduction in the number of visits to ED if two walk-in clinics were opened in these boroughs.
\end{abstract}

\section{Key words}

Emergency department’s utilization, Minor emergencies, Choice of ED, Material deprivation, Social deprivation

\section{I ntroduction}

Non-urgent uses of Emergency Departments throughout Canada have long presented a conundrum for hospital administrators and health service planners. On the one hand, perceptions persist that those non-urgent users contribute to overcrowding, higher costs of care and longer wait times ${ }^{[1,2]}$. On the other hand, non-urgent users do not appear to increase wait times for high-acuity patients, perceive their condition to be acute, or claim not having convenient access to primary medical services ${ }^{[1-3]}$. While non-urgent users do not affect wait times for high-acuity patients, they, themselves, tend not to be seen in a timely manner. Long waiting hours result in patients frustration, wait-room crowding and in 
many cases patients leaving without being seen (LWBS) ${ }^{[4,5]}$. Redirecting non-urgent demand to other less expensive alternatives may reduce the use of ED as it was found that access to a primary care physician was a statistically significant predictor of the likelihood and rate of emergency department utilization in low severity cases ${ }^{[6]}$.

Several studies evaluated patient and system characteristics that influence ED use for non-urgent or minor problems. Key factors include proximity to primary care providers (PCPs), age and gender ${ }^{[3]}$, and socio-economic status as predictors of ED use. High use of ED was found in association with high education level, lack of registration to a health plan, and problems of delivery of services ${ }^{[6]}$. Surveyed patients mentioned many factors affecting their preferences of PCP including proximity, satisfaction with care, worsening symptoms, unavailability of care in a regular clinic ${ }^{[7]}$ and incompatible office hours ${ }^{[8]}$. However, timely access barriers were found independently associated with ED use, even after adjusting for other socioeconomic and health-related factors ${ }^{[9]}$. Most of these studies were based on samples of administrative data and/or patient's opinions.

The purpose of this paper is to use administrative data of two regional hospitals in Sherbrooke, QC, Canada to comprehend the use of hospital emergency rooms for minor problems, to probe relationships between site of choice, diagnostic codes, and demographic variables, and to link administrative data with levels of social and material deprivation ${ }^{[10]}$.

There are three hypotheses to test on the use of ED for minor emergencies: 1) residents prefer the closest ED, 2) there are no differences in use of ED among residents in different levels of social and material deprivation, and 3) the distribution of diagnosis codes is similar in all city areas or communities.

\section{Methods}

This was a retrospective study consisting of administrative data collected from the two hospitals of the University Hospital Center in Sherbrooke, QC. The database contained all ED visits classified as CTAS levels 4 and 5 from June 30, 2006 to December 31, 2009. CTAS or the Canadian Triage and Acuity Scale is a national scheme for rating the urgency of presenting ED visit with a rating of 1 being most emergent and 5 being non-urgent. During the three and a half year period studied, 196,153 visits to the two hospitals were captured that met the criteria. In addition to CTAS level, we analyzed the visit information to determine the community of origin (by postal code), the first diagnosis assigned (ICD-9 code), date and time of the visit, arrival mode, age, sex, and gender.

\subsection{Postal codes and communities}

There are six boroughs in the city of Sherbrooke with different demographic and socioeconomic characteristics. Each borough has several communities. Because administrative databases contain no socio-economic information about the persons concerned, we introduced area based indicators. We added two geographical fields to each visit: the municipality and a number indicating the community to which the postal code belongs. For the city of Sherbrooke, we added a material and a social deprivation index ${ }^{[10]}$ as proxy measures of the community's socioeconomic conditions.

In order to understand the use of EDs by Sherbrooke residents we found the number of users per borough, its population, and then we linked the number of visits per user with Pampalon's deprivation indexes ${ }^{[11]}$. We obtained these indexes from the OEDC website ${ }^{[12]}$. These indexes are based on "six indicators selected for their known relationships with health and their affinities with material and social deprivation”. Pampalon divides the deprivation scale into two categories: social and material. The indicators for material deprivation are persons without a high school diploma; ratio employment/ population, and average personal income. The social deprivation scale considers proportion of persons living alone; the proportion of individuals separated, divorced, or widowed; and the proportion of single-parent families. We assigned a number to each quintile from 1 (most privileged) to 5 (most deprived). 


\subsection{Diagnostic codes}

Each visit may have one, several, or in rare cases no diagnostic code assigned to the encounter. In $92.6 \%$ of cases, a three or four digit ICD-9 numerical code was assigned. The remaining $7.4 \%$ of the visits only contained a word description or were missing. For cases with multiple ICD-9 codes, only the first code was included in the analysis. For patients admitted to the hospital, the diagnostic code(s) were those assigned at the time of admission.

\subsection{Geographical area and health care facilities}

Patients visiting the EDs came mainly from the Eastern Townships (called Estrie) in the Southeastern part of Quebec, Canada. According to the 2006 census, this area had 302,901 inhabitants. The area is divided into seven zones, six of them called regional county municipalities (MRC). The city of Sherbrooke is the seventh zone, smallest in area but comprising $50 \%$ of the population of the Eastern Townships. Each MRC has a local health care clinic (CLSC), four MRCs have a small hospital $(\mathrm{H})$ and there are a number of private medical practices. Two MRCs, Val Saint François and Haut Saint François have no 24/7 service and are located close to the Fleurimont hospital. Access to public and private services is free for all Canadians and permanent residents. However, access is not always possible as some doctors do not accept new patients, most clinics work on appointment only, and only a few clinics accept walk-in patients. While it is difficult to know with certainty the number of persons in this area that have a family doctor, the only accessible points of access 24/7 to primary health care for all residents are hospital emergency departments.

There are two hospitals in Sherbrooke: l'hôpital Fleurimont (HF), located in the outskirts of Sherbrooke, and a city hospital, l'Hôtel-Dieu (HD), that constitute the CHUS, Sherbrooke's university hospital center. The two hospitals offer emergency services mainly to the population of the Eastern Townships, although they admit patients in need from any other region. All patient information used in this study was decoded to protect the identity of the patients and comply with CHUS confidentiality guidelines. Our study only includes visits to these two hospitals.

\subsection{Data mining algorithms}

We used SPSS (IBM SPSS version 20) to analyze and classify the ED visits. A first description of the data was presented in a poster session ${ }^{[8]}$ including the maps obtained with ArcGIS-9 software. No statistical tests were performed as the study was not based on samples. To classify the visits and obtain insight on the factors affecting ED demand we used the Classification and Regression Tree routine (CRT) of the Decision tree module of SPSS; although other alternative methods (CHAID, QUEST, and Exhaustive CHAID) were also tested they did not produced better results in terms of the percentage of good classifications. Lieu (HD or HF) was the dependent variable. Independent variables selected were age, first diagnostic code, community, triage level, and date. Other variables like sex, mode of arrival, date and time of visit, and diagnostic code were not identified by the regression tree algorithms as important enough to create a different classification. The minimum number of cases in a parent node was set to 600 and the minimum cases in child node to 300 . The minimum improvement to continue branching was 0.005 . The classification obtained has $70 \%$ accuracy.

\section{Results}

The distribution of visits by emergency department and triage level is shown in Figure 1. On a daily basis, the city hospital, HD receives more CTAS-4 visits than the regional hospital HF and this demand seems stable in both EDs since the summer of 2008, when the ED of the city hospital HD was enlarged and renovated (see Figure 1a). The regional hospital HF has seen a decline in CTAS-5, with similar number of visits than the city HD since 2009 probably because of the remodeling of the emergency department in HD (see Figure 1b).

\subsection{Patients' choice of ED}

Over the $3 \frac{1}{2} 2$ years studied, visits are equally split between the two facilities: $49 \%$ for HD and $51 \%$ for HF. However, when considering patients' characteristics three patterns of patient utilization emerged: 1) Children less than 13.5 years old 
are taken mainly to HF, 2) Mental health conditions were primarily treated at the city HD hospital, and 3) CTAS-4 are predictably organized by place of residence with urban residents using mainly HD and more suburban and rural residents using HF. Sherbrooke residents go mainly to the city HD, as expected, except for the two boroughs closest to HF (Brompton and Rock Forest). We found diagnoses of mental illnesses mainly at the city HD and maternity related visits at HF, a choice made by the administration of the two hospitals.

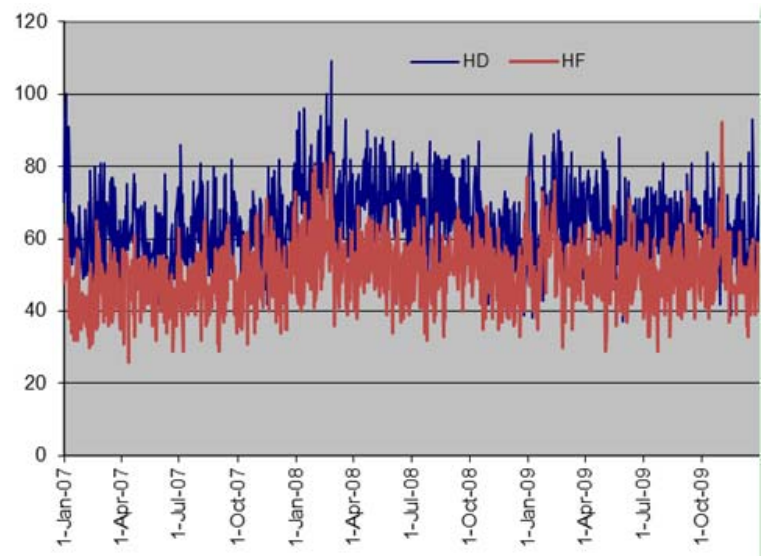

a. CTAS-4

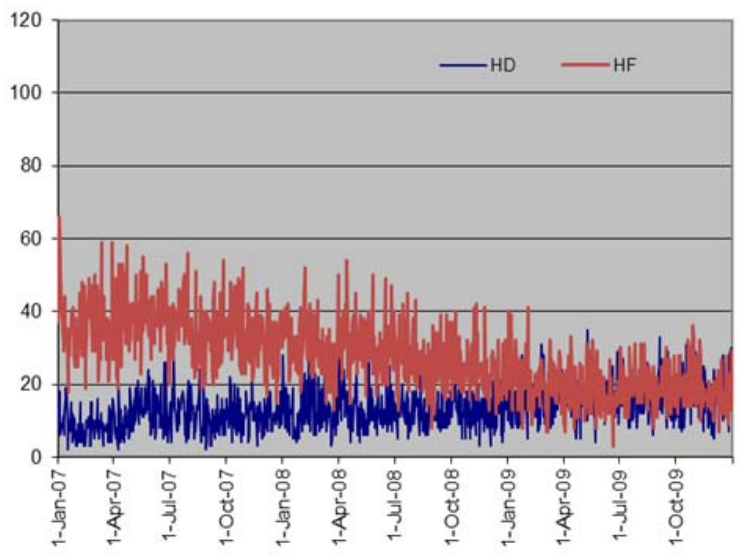

b. CTAS-5

Figure 1. Daily visits from 2007 - 2009

\subsection{Origin of visits}

Patients from the city of Sherbrooke account for almost 50\% of the population of the Eastern Townships, but they generate $70.4 \%$ of the CTAS-4 \&5 visits (see Table 1). High volumes of visits also originated from the communities of Val Saint François and Haut Saint François, representing 17.8\% and 17\% of visits respectively. It should be noted that Val Saint-François has a minor emergency room open around 12 hours per day. In the rest of the paper, we focus specifically on the demand from the population of the city of Sherbrooke.

Table 1. Distribution of visits by MRC

\begin{tabular}{llllll}
\hline \multirow{2}{*}{ MRC } & \multicolumn{5}{c}{ lieu } \\
\cline { 2 - 6 } & HD & HF & Total & Visits (\%) & pop 2006 (\%) \\
\hline Sherbrooke & 77,003 & 61,104 & 138,107 & 70.4 & 49.3 \\
Le Val-Saint-François & 5,104 & 12,882 & 17,986 & 9.2 & 9.7 \\
Le Haut-Saint-François & 6,187 & 10,654 & 16,841 & 8.6 & 7.3 \\
Memphrémagog & 3,992 & 7,092 & 11,084 & 5.7 & 15.2 \\
Coaticook & 2,692 & 3,294 & 5,986 & 3.1 & 6.2 \\
Des Sources & 1,047 & 2,235 & 3,282 & 1.7 & 4.8 \\
Le Granit & 653 & 1,071 & 1,724 & 0.9 & 7.5 \\
Not assigned & 294 & 749 & 1,043 & 0.5 & \\
Total & 96,972 & 99,081 & 196,053 & & \\
\hline
\end{tabular}

\subsection{The city of Sherbrooke}

Since 2007, the total number of CTAS-4\&5 visits decreased in total, but we observed an increase in the Mont Bellevue and Jacques Cartier boroughs (see Figure 2), with Fleurimont and Mont Bellevue consistently generating more visits than the other four boroughs. This fact can be explained partially by population as they are the most populated boroughs in Sherbrooke, but there are other important socio-economic characteristics that we present below. 


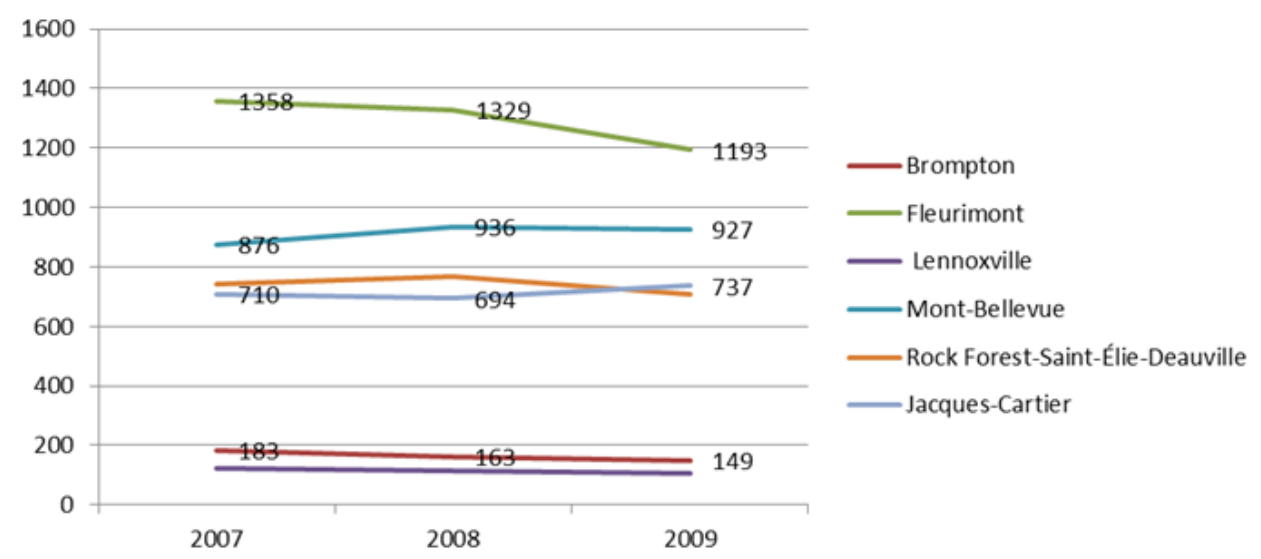

Figure 2. Evolution of the number of ED visits by borough

Figure 3 shows a high number of visits to the ED per user in areas with high deprivation indexes, either social or material. We notice many communities with a high level of social deprivation (quintile 5) and many materially privileged (quintiles 1 and 2). The most socially deprived (SDI $=4,5$ ) represent $62 \%$ of the population of Sherbrooke, whereas $64 \%$ of the population is materially privileged $(\mathrm{MDI}=1,2)$.
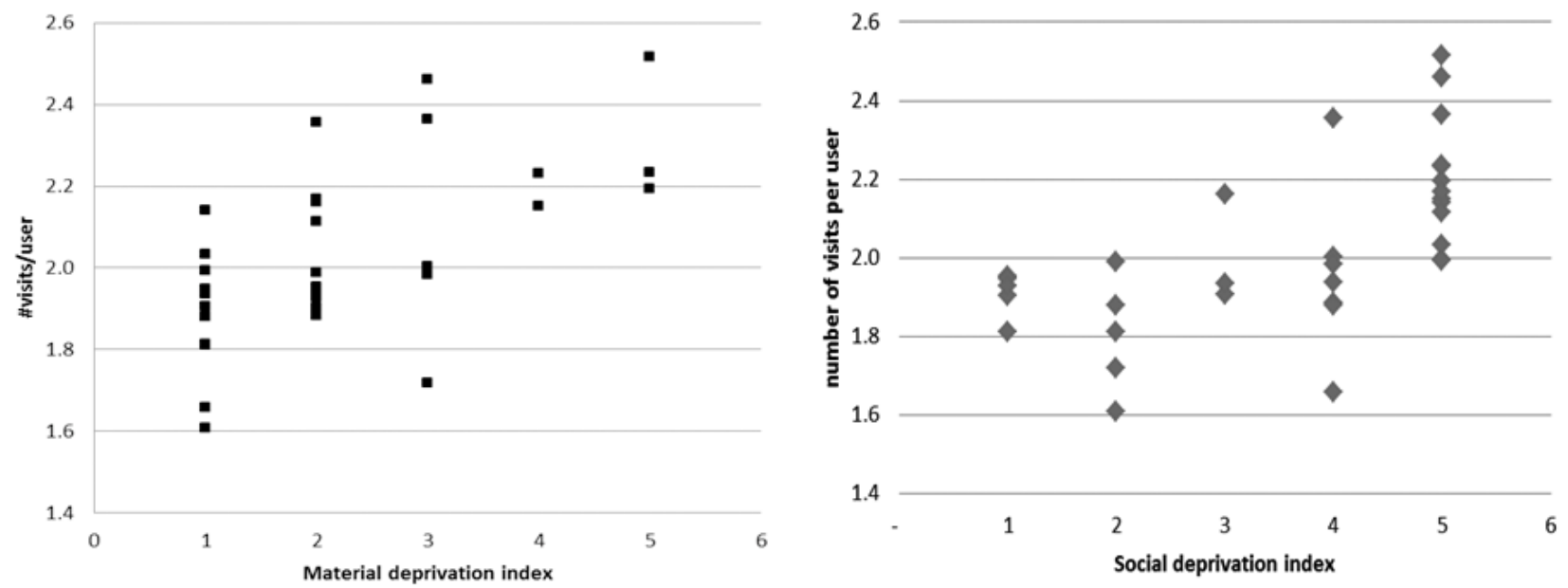

Figure 3. Number of visits per patient and by community deprivation indexes

The deprivation maps ${ }^{[13]}$ shown in Figure 4 portray each community with a color indicating the quintiles of deprivation and the percent of users from the community. These maps were prepared using the ArcGIS-9 software based on the data and charts available at the OEDC website. We observe that the percent of population using the ED is higher in more deprived communities, but the more socially deprived (SDI $=5$ ) tend to have higher usage than the more materially deprived (MDI = 5), so social deprivation is an important factor affecting the use of emergency services. The location of the two hospitals is indicated in the figures. Most of the socially deprived (red zones) live close to the city hospital HD and a large community of socially deprived lives close to the HF.

Figure 5 shows the number of visits per 100 inhabitants classified by the level of material and social deprivation. The most deprived communities (quintile 5) generated around $25 \%$ of all coded visits, with minor differences between social and material deprivation. Although we see that in very socially deprived communities a high percent of the population use the EDs, we observe that material deprivation gives larger number of visits per 100 inhabitants than social deprivation does, with larger differences in quintiles 3 and 4. 


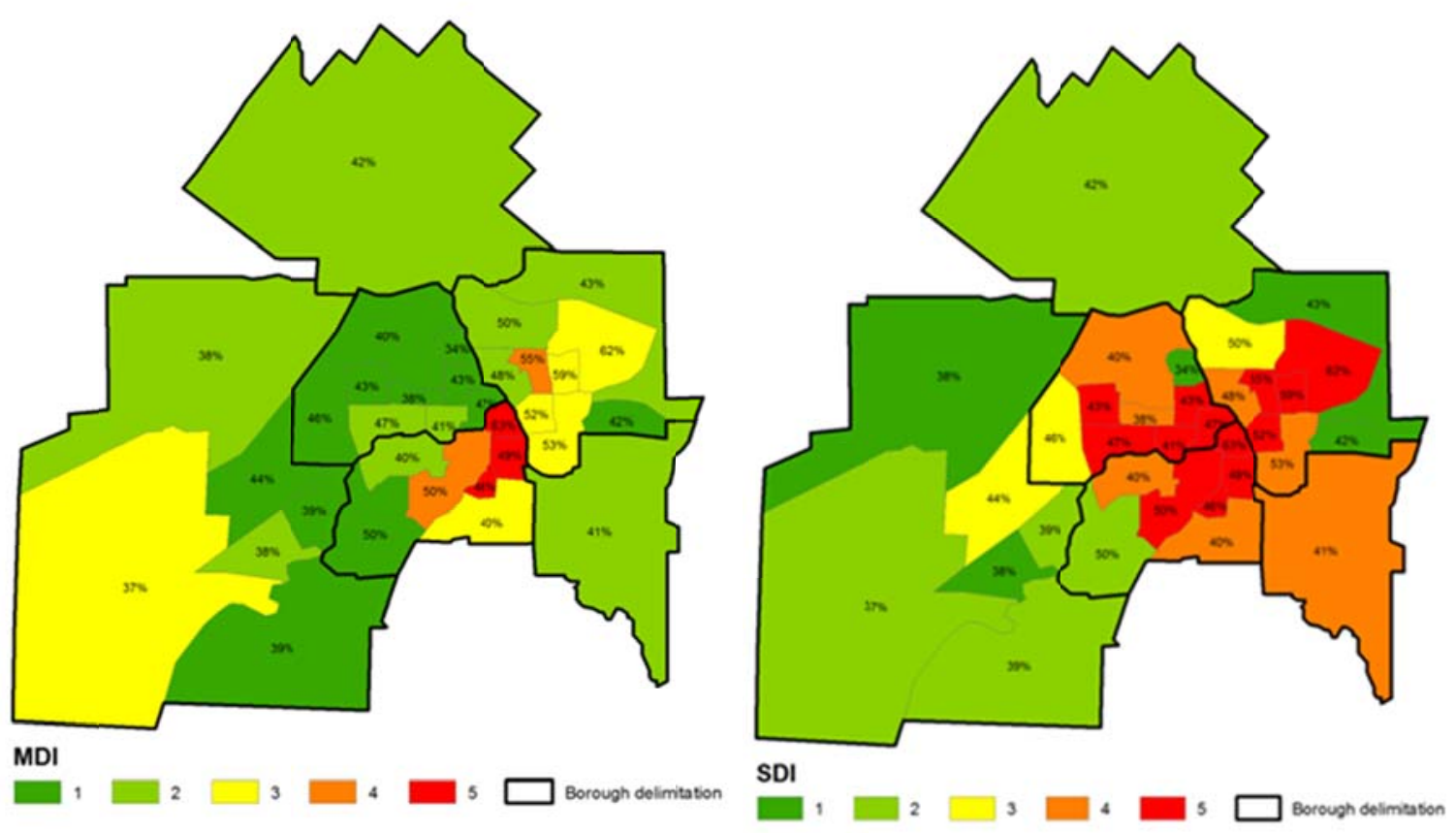

Figure 4. Percent of population using ED by communities and deprivation levels

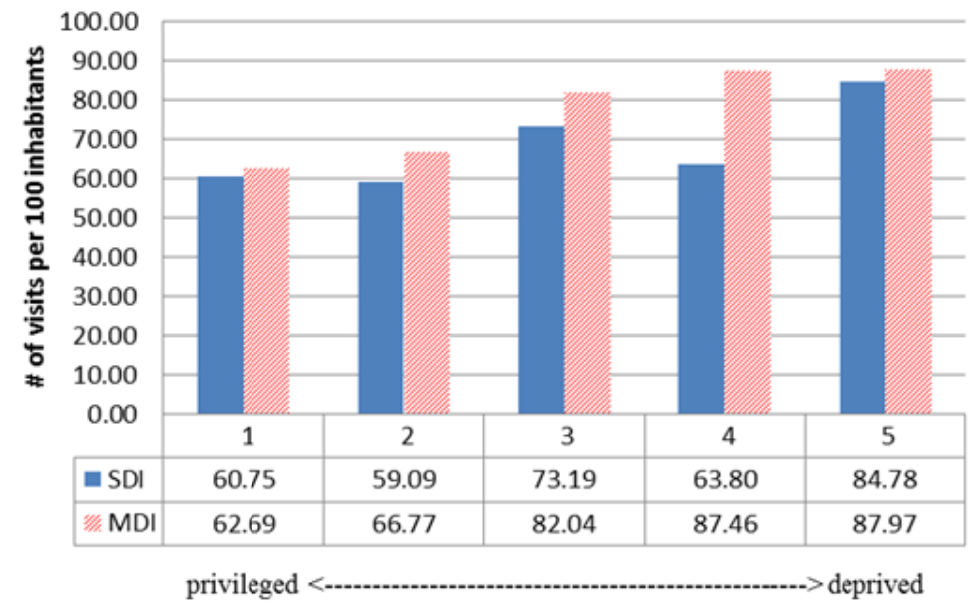

Figure 5. Use of ED by material and social deprivation of communities

The distribution of visits by borough is presented in Table 2. Overall, 44\% of the population used the ED at least once during the three and a half years of study, with two boroughs displaying a larger percent. Residents of Fleurimont and Mont Bellevue generated 57\% of all visits and had 15\% more visits per user than patients from any other borough.

We must indicate that $42 \%$ of Mont Bellevue residents live in communities with a very high level of material deprivation and $62 \%$ of residents live in communities with a very high level of social deprivation. Fleurimont has less material deprivation than Mont Bellevue, but $62 \%$ of its residents live in very high socially deprived communities. It is important to mention that these two boroughs have no primary care clinic and no walk in clinic nearby. The provision of medical services for these patients in an emergency department may well resolve the presenting situation, but may not adequately address contributing factors or manage complex conditions. Without any other alternative for such patients, the ED becomes the most convenient and obvious site for care. 
Table 2. Users and visits per borough

\begin{tabular}{llllll}
\hline Borough & \#users & \#visits & \#visits /user & users/pop & pop \\
\hline Brompton & 2,566 & 5,105 & 2 & $42 \%$ & 6070 \\
Fleurimont & 19,464 & 45,200 & 2.3 & $48 \%$ & 40255 \\
Lennoxville & 2,258 & 4,379 & 1.9 & $41 \%$ & 5545 \\
Mont Bellevue & 15,085 & 33,515 & 2.2 & $46 \%$ & 33060 \\
Rock Forest - St Elie -Deauville & 11,719 & 22,545 & 1.9 & $38 \%$ & 30755 \\
Jacques Cartier & 13,219 & 27,363 & 2.1 & $42 \%$ & 31745 \\
Sherbrooke-total & 64,311 & 138,107 & 2.1 & $44 \%$ & 147430 \\
\hline
\end{tabular}

\subsection{Main diagnostic codes}

With the exception of the 7\% not coded visits from Sherbrooke residents, we aggregated all diagnostic codes into ICD9 clusters ${ }^{[14]}$. The clusters were sorted by total incidence, by triage code, and by hospital ED (see Table 3). The city hospital HD received more visits than the regional hospital HF, with CTAS-4 visits comprising more than twice the number of CTAS-5 visits, as shown previously in Figure 1.

Table 3. Distribution of the most frequent diagnostic codes in Sherbrooke

\begin{tabular}{|c|c|c|c|c|c|c|c|c|}
\hline \multirow{3}{*}{ IDC_1 code } & \multicolumn{3}{|c|}{ Triage 4} & \multicolumn{3}{|c|}{ Triage 5} & \multirow{3}{*}{ Total } & \multirow{3}{*}{$\%$} \\
\hline & \multicolumn{2}{|c|}{ Lieu } & \multirow{2}{*}{ Total } & \multicolumn{2}{|c|}{ Lieu } & \multirow{2}{*}{ Total } & & \\
\hline & HD & HF & & HD & HF & & & \\
\hline Injury and poisoning & 12,214 & 6,712 & 18,926 & 1,804 & 3,857 & 5,661 & 24,587 & $19 \%$ \\
\hline Left without seeing doctor & 8,352 & 2,746 & 11,098 & 4,093 & 4,015 & 8,108 & 19,206 & $15 \%$ \\
\hline Ill-defined conditions & 6,623 & 4,707 & 11,330 & 687 & 1,790 & 2,477 & 13,807 & $11 \%$ \\
\hline Respiratory System & 4,743 & 4,792 & 9,535 & 924 & 3,075 & 3,999 & 13,534 & $11 \%$ \\
\hline Digestive System & 4,615 & 3,057 & 7,672 & 411 & 1,116 & 1,527 & 9,199 & $7 \%$ \\
\hline Skin and subcutaneous tissue & 3,896 & 2,092 & 5,988 & 883 & 1,854 & 2,737 & 8,725 & $7 \%$ \\
\hline Mental illness & 5,834 & 483 & 6,317 & 426 & 204 & 630 & 6,947 & $5 \%$ \\
\hline Circulatory system & 2,764 & 2,535 & 5,299 & 322 & 1,144 & 1,466 & 6,765 & $5 \%$ \\
\hline Nervous System \& Sense Org & 2,473 & 2,517 & 4,990 & 464 & 1,284 & 1,748 & 6,738 & $5 \%$ \\
\hline Other & 6,978 & 6,173 & 13,151 & 1,812 & 3,976 & 5,788 & 18,939 & $15 \%$ \\
\hline Total & 58,492 & 35,814 & 94,306 & 11,826 & 22,315 & 34,141 & 128,447 & $100 \%$ \\
\hline
\end{tabular}

The largest number of visits with a code was for Injury and poisoning (19\%), left without seeing a doctor (15\%), ill-defined conditions (11\%), diseases of the respiratory system $(11 \%)$, of the digestive system $(7 \%)$, of the musculoskeletal system (7\%) and mental illnesses (5\%). These six clusters represent $75 \%$ of the coded visits. Mental illness is the most frequent one in CTAS-4 at the city hospital HD (see Table 3). We found strong statistical evidence (chi-square test $p$ $\sim 0$ ) that the distribution of clusters between the two ED is different, even if considering triage level. We also tested the distribution of IDC9 clusters by social deprivation and by material deprivation, with similar results; incidence of diagnostic codes is not the same (chi-square test $p \sim 0$ in both tests). However, the descending order of incidence of the diagnostic codes is very similar if we consider the population in each quintile, but the frequency of such cases is quite different as show below.

We calculated the number of visits per 100 residents classified by deprivation indexes, omitting the persons that left without seeing a doctor. In Table 4 below, we observe high frequency of visits for all high levels of material deprivation in all main diagnostic codes. The greatest gap is found in mental illnesses where visits per 100 residents in materially deprived communities more than doubled those in the total population. This result is similar to other studies in the USA where persons with Medicaid coverage were more likely to have had at least one emergency department (ED) visit in a 12-month period than those in other insurance groups ${ }^{[15]}$. 
Table 4. Visits per 100 residents by material deprivation index

\begin{tabular}{|c|c|c|c|c|c|c|}
\hline \multirow{2}{*}{ IDC9 cluster } & \multicolumn{5}{|c|}{ 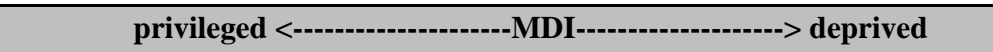 } & \multirow[b]{2}{*}{ Total } \\
\hline & 1 & 2 & 3 & 4 & 5 & \\
\hline Injury \& poisoning & 14.76 & 16.19 & 18.17 & 20.03 & 18.67 & 16.68 \\
\hline Ill-defined conditions & 8.26 & 8.60 & 10.76 & 11.32 & 11.21 & 9.37 \\
\hline Respiratory system & 8.09 & 8.63 & 10.62 & 10.12 & 10.97 & 9.18 \\
\hline Digestive system & 5.54 & 5.63 & 7.00 & 7.72 & 7.86 & 6.24 \\
\hline Musculoskeletal & 4.85 & 5.37 & 7.21 & 7.62 & 7.25 & 5.92 \\
\hline Mental illnesses & 3.35 & 3.30 & 5.53 & 7.58 & 10.07 & 4.71 \\
\hline Other & 36.09 & 37.91 & 48.07 & 49.75 & 52.43 & 41.58 \\
\hline total & 80.95 & 85.62 & 107.36 & 114.14 & 118.46 & 93.68 \\
\hline
\end{tabular}

A similar finding was observed when calculating the number of visits per 100 residents according to social deprivation index (see Table 5). The descending order of frequency is almost the same in all levels of social deprivation but again we find higher values in socially deprived communities. We find that respiratory conditions are the second diagnostic code for quintiles 1-3, the more socially privileged communities, whereas it comes third in the more deprived ones. Communities with high social deprivation had 7.35 visits for mental illnesses per 100 residents, compared to 4.71 for the total population of Sherbrooke.

Table 5. Visits per 100 residents by social deprivation index

\begin{tabular}{|c|c|c|c|c|c|c|}
\hline \multirow{2}{*}{ IDC9 cluster } & \multicolumn{6}{|c|}{ privileged <---------------------SDI--------------------> deprived } \\
\hline & 1 & 2 & 3 & 4 & 5 & Total \\
\hline Injury \& poisoning & 15.78 & 14.46 & 17.31 & 15.49 & 18.26 & 16.68 \\
\hline Ill-defined conditions & 7.25 & 7.27 & 8.62 & 8.33 & 11.57 & 9.37 \\
\hline Respiratory system & 8.68 & 8.36 & 10.47 & 7.40 & 10.29 & 9.18 \\
\hline Digestive system & 4.93 & 4.83 & 6.65 & 5.55 & 7.48 & 6.24 \\
\hline Musculoskeletal & 4.59 & 4.36 & 6.11 & 5.43 & 7.16 & 5.92 \\
\hline Mental illnesses & 2.05 & 2.30 & 3.19 & 3.77 & 7.35 & 4.71 \\
\hline
\end{tabular}

\section{Discussion}

In our first hypothesis, we stated that proximity plays a major role when choosing which ED to visit, with the closest ED being the preferred site. Overall, there is almost an equal split in the number of visits CTAS-4 and CTAS-5 between the two EDs. However, when we included population characteristics, children were taken to the regional hospital (HF) regardless of the distance. We can only speculate that the HF enjoys an excellent reputation, and it may be the birthplace of many such children, as the other hospital has no maternity ward. Other users with CTAS-4 conditions chose the closest ED for most diagnostic codes. For all users older than 13.5 years old choosing the closest site is coherent with previous work on other populations ${ }^{[3]}$.

Our second hypothesis stated that there is no difference in the use of EDs among the communities. The most deprived communities (quintile 5) generated around $25 \%$ of all coded visits, with minor differences between social and material deprivation. Therefore, communities with high levels of deprivation have a higher use of EDs.

The third hypothesis stated no differences in the prevalence of diagnostic codes among the population and we found that the six main IDC9 clusters appear in the same descending order for most communities. The large differences occur in the frequency of such diagnostic codes, with mental illnesses occurring more than twice in materially deprived communities than they do in the overall population of Sherbrooke. 
We must point out that 7\% of visits were either incomplete or had no diagnostic code. Therefore, the distribution of first diagnostic codes is based on $93 \%$ of registered visits and this may have introduced a bias in the results. The users leaving before seeing a doctor (14\%) received a CTAS-4 in $68 \%$ of the cases and $65 \%$ occurred at the city hospital HD. The analysis of these visits will be further studied.

We found two city boroughs generating larger percent of visits to the EDs also have a larger percentage of their population living in communities with very strong social deprivation. Although it is impossible to eliminate all minor emergency visits, it is well documented ${ }^{[16-18]}$ that regular access to primary care services results in better health outcomes. This would also hold true for mental health patients, harder to manage, and who most likely not have access to the follow-up care they may need in the context of an ED. We suggest that Fleurimont and Mont Bellevue - that had no primary care clinic and make high use of the ED for non-urgent conditions could benefit from an expansion of primary care services. We estimate there is potential for sizable cost savings by establishing walk-in services in these communities. We may see that if the percent of their population using the ED go down to around $40 \%$ (instead of $48 \%$ and $46 \%$ respectively) on average, there would be a reduction in non-urgent and less-urgent use of the ED by roughly 14,000 visits per year.

\section{Conclusions}

It is alleged ${ }^{[19]}$ that one of the main problems with the health care system in Canada is the emphasis placed over the last 40 years on acute care (i.e., hospitals) to the neglect of primary care. Our findings are probably a result of this trend, suggesting that for certain populations, the acute care setting have become the only setting in which to receive care. As we plan health services for socially deprived communities with limited access to primary care such as those described here, we must consider the impact of minor emergency visits on the overall quality of healthcare.

Our analysis of administrative data linked to census data through deprivation indexes provided evidence-based research that highlights areas requiring better access to primary care, identified social deprivation as an important factor of ED use, and constitutes a base scenario for future analyses of minor emergency visits.

\section{Acknowledgements}

We wish to acknowledge the assistance of Pierrot Richard from the ASSSE ${ }^{[16]}$ in linking postal codes and communities, and of Suzan Taylor in preparing the deprivation maps. This work was partially funded by a research grant from Bishop's University. Special thanks to Paul Rueckhaus for his careful reading of this work; his comments and insight greatly improved this paper.

\section{References}

[1] Madison, A. R. Myth: Emergency Room overcrowding is caused by non-urgent cases. Can. Health Svc. Rsch. Fndtn: Myth Busters. 2009. Available from: http://www.cfhi-fcass.ca/Libraries/Mythbusters/Myth-Emergency-Rm-Overcrowding-EN.sflb.ashx.

[2] Field, S., Lantz, A. Emergency department use by CTAS Levels IV and V patients. Can. J. of Emerg. Med. 2006; 8(5): 317-322.

[3] Zubieta, L., S. Béquet. Factors of primary care demand: A case study. Rural and Remote Health. 2010; 10: 1520. Available from: http://www.rrh.org.au/articles/showarticlenew.asp?ArticleID=1520. PMid: 21108533.

[4] Rowe, B.H., Channan, P., Bullard, M., Blitz, S., Saunders, L.D., Rosychuk, R.J., et al. Characteristics of patients who leave emergency departments without being seen. Academic Emerg. Med. 2006; 13: 848-852. PMid: 16670258. http://dx.doi.org/10.1111/j.1553-2712.2006.tb01735.x

[5] Schull, M.J., Kiss, A., Szalai, J.P. The effect of low-complexity patients on emergency department waiting times. Annals of Emergency Medicine. 2007; 49(3): 257-264. PMid: 17049408. http://dx.doi.org/10.1016/j.annemergmed.2006.06.027

[6] Lee A, Lau FL, Hazlett CB, Kim CW, Wong P, Wong TW, et al. Factors associated with non-urgent utilization of Accident and Emergency services: a case-control study in Hong Kong. Soc Sci Med. 2000; 51(7): 1075-85.

http://dx.doi.org/10.1016/S0277-9536(00)00039-3

Published by Sciedu Press 
[7] Oktay C, Cete Y, Eray O, Pekdemir M, Gunerli A. Appropriateness of emergency department visits in a Turkish university hospital. Croat Med J. 2003; 44(5): 585-91. PMid: 14515418.

[8] Carret ML, Fassa AG, Kawachi I. Demand for emergency health service: factors associated with inappropriate use. BMC Health Serv. Res. 2007; 7: 131. PMid: 17705873. http://dx.doi.org/10.1186/1472-6963-7-131

[9] Rust G, Ye J, Baltrus P, Daniels E, Adesunloye B, Fryer GE. Practical barriers to timely primary care access: impact on adult use of emergency department services. Arch Intern Med. 2008 Aug 11; 168(15): 1705-10. PMid: 18695087. http://dx.doi.org/10.1001/archinte.168.15.1705

[10] Pampalon R, D. Hamel, P. Gamache, G. Raymond. A deprivation index for health planning in Canada. Chronic Diseases in Canada. 2009; 29(4): 178-191. PMid: 19804682.

[11] Pampalon R, D. Hamel, P. Gamache, M. Philibert, G. Raymond, A. Simpson. An Area-based Material and Social Deprivation Index for Public Health in Québec and Canada. CANADIAN JOURNAL OF PUBLIC HEALTH. 2012; 103(Suppl. 2): S17-S22. PMid: 23618066.

[12] OEDC. (Observatoire estrien du développement des communautés) Population data and charts. 31/01/2013. Available from: http://www.oedc.qc.ca/tableau-de-bord/donnees/06

[13] Zubieta L, S. Taylor. Characteristics of Minor Emergency Visits. Poster presented at the Health Users Conference. 2012; Ottawa, Canada.

[14] Ministry of Health. Government of British Columbia, Canada. Available from: http://www.health.gov.bc.ca/msp/infoprac/diagcodes

[15] Garcia TC, Bernstein AB, Bush MA. Emergency department visitors and visits: who used the emergency room in 2007? NCHS Data Brief. 2010 May; (38): 1-8.

[16] Marriott, J., Mable, A.L. Sharing the Learning: Health Transition Fund: Synthesis Series: Primary Health Care. Ottawa: Health Canada. 2002.

[17] Doupe MB, Palatnick W, Day S, et al. Frequent users of emergency departments: developing standard definitions and defining prominent risk factors. Ann Emerg Med. 2012; 60(1): 24-32. PMid: 22305330.

http://dx.doi.org/10.1016/j.annemergmed.2011.11.036

[18] Bieler G, Paroz S, Faouzi M, et al. Social and medical vulnerability factors of emergency department frequent users in a universal health insurance system. Acad Emerg Med. 2012; 19(1): 63-8. PMid: 22221292. http://dx.doi.org/10.1111/j.1553-2712.2011.01246.x

[19] Roberge, D. R. Pineault, D. Larouche The Continuing Saga of Emergency Room Overcrowding: Are We Aiming at the Right Target? HEALTHCARE POLICY. 2010; Vol.5 No.3. 